\title{
Risks and safety in construction by increasing efficiency of investments
}

\author{
Victoria Borkovskaya ${ }^{1^{*}}$, Elena Lyapuntsova ${ }^{2}$ and Maxim Nogovitsyn ${ }^{2}$ \\ ${ }^{1}$ Moscow State University of Civil Engineering, Yaroslavskoe shosse 26, Moscow, 129337, Russia \\ ${ }^{2}$ Bauman Moscow State Technical University, 2-ya Baumanskaya st.5/1, Moscow 105005, Russia
}

\begin{abstract}
This study focuses on enhancing the effectiveness of investment in construction given the constant threat of new risks. We investigate the types and causes of risks of firms working in the construction industry, draw conclusions about the importance of risks associated with the investment attractiveness of projects, as well as responsibility for the environmental safety. Urbanization and changes in the surrounding area are the dominant trend in the development of modern society. The constant demand of business for commercial real estate, as well as the increase in population growth demands enhanced effectiveness in the construction market, where supply in construction market depends on the economic conditions. The relevance of the research topic is due to the fact that the increasing capital flows in the construction industry pose new challenges for forecasting, statistics and risk control, and a focus on the rates of return mechanisms to hedge against the uncertainty of the future. The aim of the study is a systematic integrated approach to solving problems to improve the efficiency and effectiveness of investments and their protection using a methodological systematic approach, which considers the components of an integrated investment process. We propose a model of risk hedging management, and focus on an analytical methodology of the most relevant risks in modern construction.
\end{abstract}

\section{Introduction}

The GSP Global Forecast for 2030 defines construction as one of the fastest growing industrial sectors over the next eleven years, with great investment potential and new horizons. The numbers are colossal: it is believed that construction in the world and the markets adjacent to it will grow by $85 \%$ to 17.5 trillion dollars. By 2030, it will account for about $15 \%$ of the total world production, involving new jobs, creating competitive advantages for stakeholders and, in fact, creating an incentive for economic growth. In general, it is expected that the construction industry will actively grow at an average of $3.9 \%$ per year, more than one percentage point faster than GDP. However, the dynamics will vary not only depending on the region or country, but also on the solution of existing and newly created risks. [1-3]

\footnotetext{
*Corresponding author: BorkovskayaVG@mgsu.ru, Lev77@me.com, maxyboyder@gmail.com
} 
In the construction sector there are various risks that affect the success of a company. This article aims to identify the most relevant risks inherent in construction companies, with particular attention to the group of financial and economic risks and the creation of the final output in this industry. Studies have shown that the construction industry is subject to multiple sources of internal and external risk, highlighting the investment climate, inflation, the dynamics of effective demand, and social responsibility for the safety of projects. [1-9]

\section{Materials and Methods}

"The investment of an enterprise is the investment of capital in all its forms in various objects (tools) of its economic activity for the purpose of making a profit, as well as achieving a different economic or non-economic effect, the realization of which is based on market principles and is associated with factors of time, risk and liquidity" . [9] There are several areas of investment related to construction. Such as the reconstruction and construction of commercial premises, warehouse construction, industrial facilities, exhibition centers and much more. Each of these areas has its own characteristics, ranging from dates, shares, scale of facilities, country differences and percentage of profitability. The material and financial resources spent are significantly different. As a result, some financial institutions and investors do not invest in construction projects, explaining their actions are due to increased level of risk in construction industry. [6-9]

According to the ISO 31000 international risk management standard in construction projects, risk can be defined as the probability of an event that impairs the viability of a project [10] Not all risks should be associated with negative results, because, although in most cases this happens, risks can also mean potential opportunities. From the time the project objectives are set, construction time, cost, and quality are the most important risk factors to consider. The main problem is that these risks are not always competently considered in the construction industry [11]. Risk management is the process of identifying, analyzing and responding to risks throughout the life cycle of a project to control, mitigate or eliminate these risks. In order to properly eliminate risks, we must first identify internal risks in the construction sector, and in the second stage and after analyzing them, focus on external risks, especially in the investment and financial sector. Proper identification and distribution of risk will reduce the negative consequences, increasing the profitability and effectiveness of management [12]. There are a large number of risk classifications. Based on the analysis of investment attractiveness, the following can be distinguished: financial risk, technological risk, economic risk, organizational risk, management risk, time risk and legal risk. Each project can be analyzed according to a so-called checklist or a check list of a specific project. However, given the unique nature of each project, the variety of conditions for the execution of works, the checklist has a flexible structure, allowing to take into account the risk factors necessary for the investor or the construction company, those that have a significant impact on the performance of work. This article aims to identify, classify and analyze the most significant risks inherent in large engineering or construction projects, with particular attention to the group of economic risks and the development of a final conclusion. [3,12-14]

Since 1988, the Aberdeen Group has published studies that help businesses around the world to improve their performance. Thus, the Agency conducted a study [15] on the most significant economic risk factors in the construction industry. 


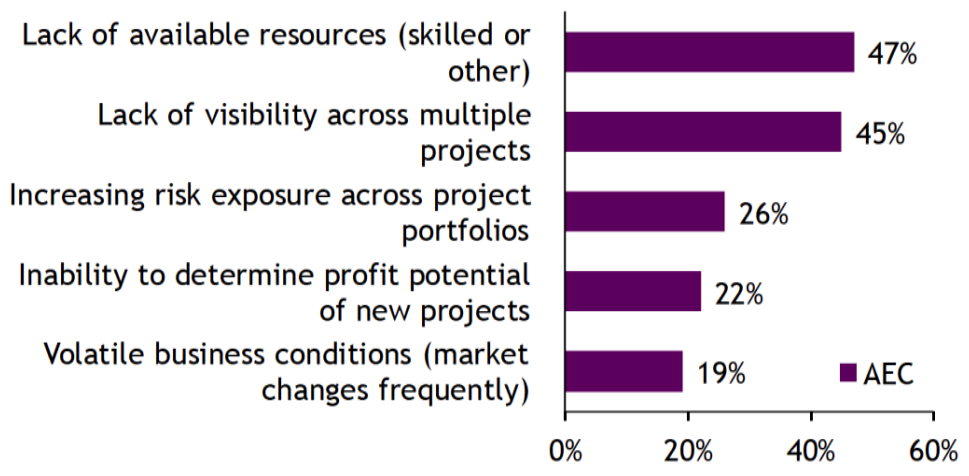

Percentage of Respondents, $\mathrm{n}=73$

Source: Aberdeen Group, October 2018

Fig.1. Top Challenges for Construction Firms

The chart shows that in the sample, the largest number of AEC respondents (firms in the fields of architecture, engineering, and construction) noted that the lack of resources, including professional skills, increased the risk of failure of the project or its partial failure.

Due to the lack of strategic vision, firms in the construction industry are not able to manage their resources effectively, complete projects, monitor costs and predict future profits. Also, construction firms do not have full access to the information they need to make effective decisions.

In modern conditions, to complicated high-risk, profit may be reduced, and the projects will never make it in the time frame and scope of the established budget.

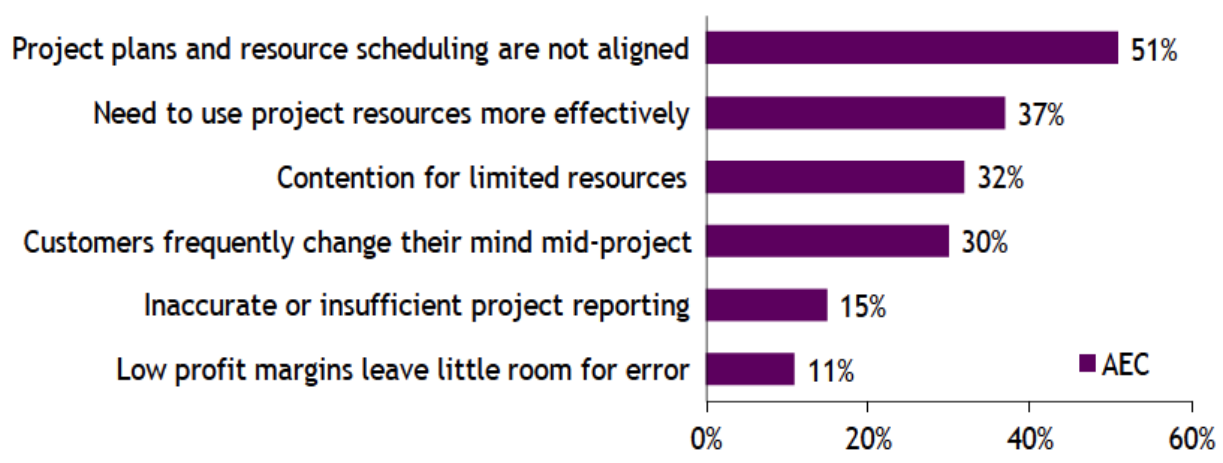

Percentage of Respondents, $n=73$

Source: Aberdeen Group, October 2018

Fig. 2. Top Project-Specific Challenges for Construction Firms

Given the lack of resources in construction companies, the companies strive to enhance their effectivenss and efficiency of their available labor and materials. However, without a full understanding of the demand or availability of these resources, it is extremely difficult to manage costs effectively. Problems with the lack of manpower to pursue the construction, and the rise of construction after the recent recession, human resources departments are trying to fill positions to keep up with the growing demand for their services. [16,17]

Despite the fact that in 2018, the construction sector has increased 170,000 people, the demand for new staff is constantly increasing. "According to the latest report of the Bureau 
of labor statistics (JOLTS), showing vacancies in June in the construction was 263, 000. To fill vacancies, many construction firms hire workers with little or no construction experience. This is not always a negative factor, but there are additional risks associated with the presence of less experienced staff. These people will not have the same skills as experienced workers, which means they will be less productive and may need more supervision when they start working." [18]

In the management of construction project investors and stakeholders are trying to manage costs with incomplete reporting, making the difficult determination of profitability, at the same time as managing the project and controlling the time for compliance with the budget.

Also, lack of accountability can make communication with the external environment much more difficult. The need to ensure that customers ' expectations are met, and materials from suppliers are delivered on time and at a reasonable price, and subcontractors are competent - a difficult test. Existing reporting standards, as well as regulatory requirements relating to materials, workers and environmental safety. "The authors of Crucial Conversations conducted a survey of 1,500 employees in 22 organizations and found that $93 \%$ of employees say that their working group is currently under threat because of a security issue that is not discussed."Trust and the quality of relationships strongly affect the safety and overall productivity of employees. All the described processes impose on construction organizations the task of continuous improvement of their capabilities, strategic vision and communication with the environment. [11]

\section{Results and Discussion}

Typically, risk factors in a project can be classified based on their sources and impact on the project objectives and can be external, internal and legal categories. The following detailed figure provide a convenient grouping of project risks typically classified according to the source. [19]

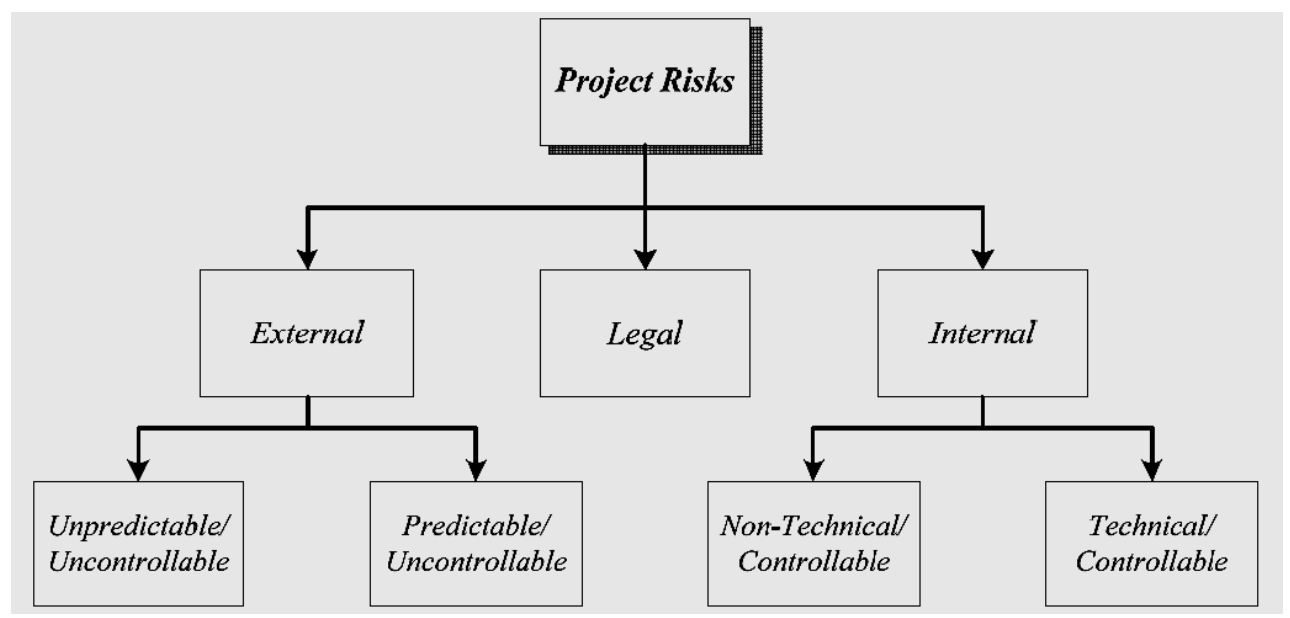

Fig. 3. Classification of project risks

Awareness of the need to reduce risks in the industry and their effective reduction depends on the coordinated work of all participants in the construction process, including the most significant institutional investors (banking organizations, financial companies, pension funds). The task of the financier is to provide capital investments for the successful implementation of the project with the priority of future return on investment while 
minimizing costs. Thus, the goal of the participants of the construction project is to successfully implement the conditions for project effectiveness. However, there are often conflicting incentives. Financial institutions seek to minimize risks and therefore are interested in increasing the return on capital from the first stages of construction. The developer, in turn, seeks to slow down the sales process at the final stages of construction, and when it is put into operation and the cost of the building will be maximum. This conflict of interest is a consequence of the balance sheet: the higher the yield, the greater the investment risks borne by the investor. Partially, this conflict can be resolved with the help of the state who can observe the big picture and optimally resolve the conflicting incentives. [20-24]

To date, there are a large number of public-private projects that provide support in various industries, including construction. Financial support for industrial production is provided in the forms provided by law, and it can provide funds for the development of industry. These funds are the organizations which are a part of infrastructure of support of activity in the sphere of the industry, and provide financial support to these activities within subjects of activity in the sphere of the industry in the form of loans, grants, contributions to authorized capital, and financial lease (leasing).

Burke Rory [25] makes recommendations for successful risk management necessary to control and reduce the negative consequences of risks: Focus on the most significant risks; Consider various options for risk management; Understand the effective distribution of risks; Assess the factors that may affect the willingness of the party to take risks; Assess the response from the outside; Determine the context of the work and success plan.

The process of risk management project (PRMP)

Pay attention to the recommendation of the PMBOK system - which is a field of knowledge on project management (project Management Body of Knowledge, PMBoK) presenting a systematic knowledge base on project management. The project management Institute uses this document as the main information material, guidance for its professional development programs. Let's now define PMP (Project Risk Management Process). In determining we also learn about the risk management of the construction project as a whole. We will also understand how our process relates to the 6 processes defined in the PMBOK Manual, where all the components are shown in figure [26]

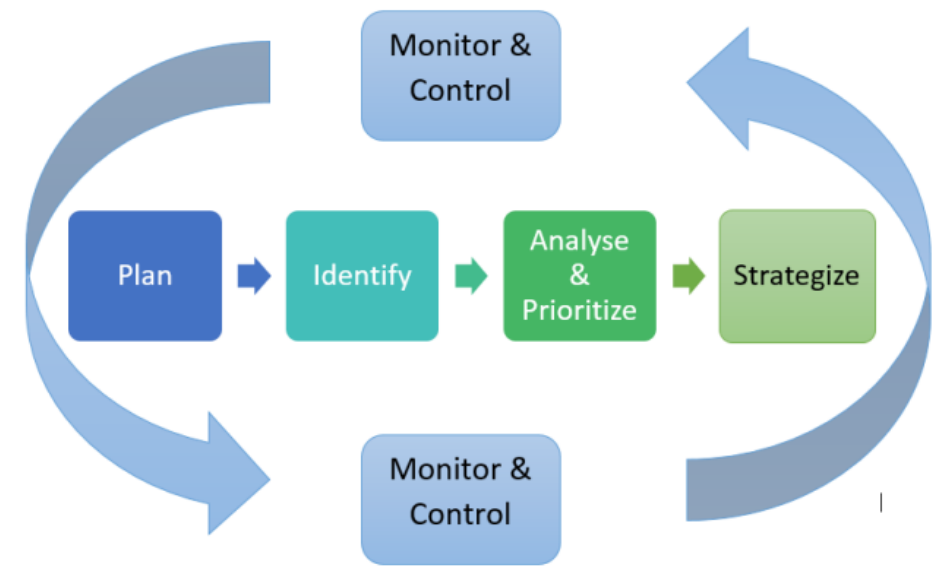

Fig. 4. Project Risk Management Process

Action 1-Plan. The process begins with risk management planning (RM), including items:

- List of events 
- Responsibilities related to the activities of

- Budget allocated for activities

- Duration of activities

- Communication and reporting for activities

Action 2-Definition. The next step is to identify risks for the project and create a structured list:

- Identify risk characteristics

- Identify symptoms, root causes and triggers

- Describe the impact on the project objectives

Action 3-Analysis and prioritization. The next logical step will be to analyze all the risks listed and prioritize future actions, including:

- Analysis of the probability of each risk

- Analysis of the impact of each risk

- Analysis of the urgency of each risk

- The priority of each risk

Action 4-Strategy. The next logical step is to plan the risk response for the priority risks:

- Identification of risks responses to threats

- Identification of risk responses to opportunities

Action 5-Monitoring and management. Since the risks are uncertain and are planned for the future, monitoring should be ongoing. Note that the previous 4 actions must be performed continuously and without stopping, as there is a great threat of new risks.

- Monitoring of all identified risks

- Control risks with planned and unplanned Analytics

- Assessing the effectiveness of the risk process

\section{Conclusions}

Summing up the above, we came to the conclusion that identifying and determining a large number of current risks in the construction industry and the environment, we can say that the industry has a multifactorial structure that can affect the final result in the form of construction of the building, construction of the object, renovation of premises, etc. Determine that the dominant risk is uncertainty and lack of information, which greatly affects all participants in the construction process. The impossibility of careful detailing of the future imposes additional costs on the developer, staff and stakeholders. However, the transfer of responsibility by the insurance agent is only part of the solution. Constantly changing market conditions, including economic downturns, exchange rates, inflation and consumer demand reduction and changes in the labor market shows the need to control the probability of an unfavorable outcome of the event. Modern methods of management and Analytics allow to protect investments from losses, including such methodological manuals as PMBOK, cloud technologies, formation of strategic vision of the future and expert assessments. Also, continuous training on past projects and improvement of employees ' skills on their own experience in the field of risk identification is a positive approach to training.

Summarizing the work done, using the experience and scientific basis for minimizing the financial and economic risks described above in the implementation of investment construction projects, it is possible to create conditions for investment in construction projects and related infrastructure more profitable and less uncertain. 


\section{References}

1. Borkovskaya V.G. The concept of innovation for sustainable development in the construction business and education. Applied Mechanics and Materials. (Volumes 475476). Chapter 15: Engineering Management. December 2013. Pages 1703-1706. DOI: 10.4028/www.scientific.net/AMM.475-476.1703

2. BorkovskayaV.G. Bardenwerper W. Roe R. Interactive Teaching of Risk Management in the Russian Construction Industry. IOP Conf. Series: Materials Science and Engineering 365 (2018) 062030 doi:10.1088/1757-899X/365/6/062030

3. Borkovskaya V.G., Degaev E., Burkova I. Environmental economic model of risk management and costs in the framework of the quality management system // MATEC Web of Conf.,193 (2018) $05027 . \quad$ DOI: https://doi.org/10.1051/matecconf/201819305027.

4. Roe R., Bardenwerper W, Borkovskaya V.G. Using a Case Study Interactively to teach Sustainability Risk Management. Journal MATEC Web of Conferences, Volume 251, 06028 (2018). DOI:

5. Borkovskaya V.G, Bardenwerper W, Roe R. Sustainability Risk Management: The Case for Using Interactive Methodologies for Teaching, Training and Practice in Environmental Engineering and Other Fields. Advances in Economics, Business and Management Research (France-Netherlands). Atlantis Press. In press.

6. Burkov V.N., Burkova I.V., Barkhi R., Berlinov M. Qualitative Risk Assessments in Project Management in Construction Industry. Journal MATEC Web of Conferences, Volume 251, 06027 (2018). DOI: https://doi.org/10.1051/matecconf/201825106027

7. Lyapuntsova E., Belozerova Iu., Drozdova I., Afanas'ev G., Okunkova E. Entrepreneurial Risks in the Realities of the Digital Economy. Journal MATEC Web of Conferences, Volume 251, $06032 \quad$ (2018). DOI: https://doi.org/10.1051/matecconf/201825106032

8. Borkovskaya V.G. Environmental and economic model life cycle of buildings based on the concept of "Green Building". Applied Mechanics and Materials 467. Materials Science and Mechanical Engineering. Chapter 2: Building Materials and Construction Technologies. Pages 287-290. December 2013. DOI: 10.4028/www.scientific.net/AMM.467.287

9. Lyapuntsova E., Belozerova Iu., Drozdova I., Berlinova M. Investment Risks in the Field of Social Entrepreneurship. Journal MATEC Web of Conferences, Volume 251, 06019 (2018). DOI: https://doi.org/10.1051/matecconf/201825106019

10. ISO 31000:2018 (E)

11. Mills A. A systematic approach to risk management for construction. Structural Survey (2016)

12. Borkovskaya V.G. Complex models of active control systems at the modern developing enterprises. Advanced Materials Research (Volumes 945-949). Chapter 22: Manufacturing Management and Engineering Management. June 2014. Pages 30123015. DOI: 10.4028/www.scientific.net/AMR.945-949.3012

13. BorkovskayaV.G, Passmore D. Behavioral engineering model to identify risks of losses in the construction industry. Advances in Economics, Business and Management Research (France-Netherlands). Atlantis Press. In press.

14. Borkovskaya V.G. Project Management Risks in the Sphere of Housing and Communal Services. Journal MATEC Web of Conferences, Volume 251, 06025 (2018). DOI: https://doi.org/10.1051/matecconf/201825106025 
15. Nick Castellina. Managing financial risk in construction project through cloud technology: keep costs and improve profits. Aberdeen Group. November 2018.

16. Polyakova V., Degaev E.,Pierre El Haddad. Reduction of Ecological and Economic Risks in Utilization of Solid Domestic Wastes and Construction Waste. MATEC Web of $\begin{array}{llll}\text { Conferences } & \mathbf{2 5 1}, & 06017 & \text { (2018). }\end{array}$ https://doi.org/10.1051/matecconf/201825106017.

17. Degaev E., Orlov A., Pierre El Haddad, Pleshivtsev A. Ecological and Economic Risks of Fire Protection of Warehouses and Tank Parks. MATEC Web of Conferences. 251, 06013 (2018). DOI: https://doi.org/10.1051/matecconf/201825106013

18. Mills A. A systematic approach to risk management for construction. Structural Survey (2018)

19. Borkovskaya V.G. Project risks. Scientific Review number 23, 2015. Moscow. 212214pp.

20. Pleshivtsev A., Korol O., Barkhi R. Risks on Optimization of Life Cycle of Technology of Installation of Transformed Low-rise Buildings from Sandwich Panels. Journal MATEC Web of Conferences, Volume 251, $06024 \quad$ (2018). DOI: https://doi.org/10.1051/matecconf/201825106024

21. Kas'yanov V.F. Danilchenko V., Amelin V.,Tolmachev V. Environmental risk management. Forecasting and modeling of emergency risk management. Journal MATEC Web of Conferences, Volume 251, 06030 (2018). DOI: https://doi.org/10.1051/matecconf/201825106030.

22. Korol O., Shushunova N., Lopatkin D., Zanin A., Shushunova T. Application of Hightech Solutions in Ecodevelopment. Journal MATEC Web of Conferences, Volume 251, 06025 (2018). DOI: https://doi.org/10.1051/matecconf/201825106002.

23. Korol E.A., Gaydysheva Y., Passmore D. Integration of organizational-technological and social aspects in the realization of the program of renovation of residential development. Journal MATEC Web of Conferences, Volume 251, 06025 (2018). DOI: https://doi.org/10.1051/matecconf/201825106025.

24. Passmore D., Chae Ch., Kustikova Yu., Baker R., Jeong-Ha Yim. An exploration of text mining of narrative reports of injury incidents to assess risk. MATEC Web of $\begin{array}{lll}\text { Conferences. } & \mathbf{2 5 1} & 06020\end{array}$

DOI: https://doi.org/10.1051/matecconf/201825106020

25. Burke, R. Fundamentals of project management: tools and techniques. 2010

26. www.pmi.org. 